\title{
Resistance to Boscalid Fungicide in Alternaria alternata Isolates from Pistachio in California
}

\author{
Herve F. Avenot and Themis J. Michailides, Department of Plant Pathology, University of California Davis, \\ Kearney Agricultural Center, Parlier 93648
}

\begin{abstract}
Avenot, H. F., and Michailides, T. J. 2007. Resistance to boscalid fungicide in Alternaria alternata isolates from pistachio in California. Plant Dis. 91:1345-1350.

Boscalid is a new carboxamide fungicide recently introduced in a mixture with pyraclostrobin in the product Pristine for the control of Alternaria late blight of pistachio. In all, 108 isolates of Alternaria alternata were collected from pistachio orchards with (59 isolates) and without (49 isolates) prior exposure to boscalid. The sensitivity to boscalid was determined in conidial germination assays. The majority of isolates from two orchards without a prior history of boscalid usage had effective fungicide concentration to inhibit $50 \%$ of spore germination $\left(\mathrm{EC}_{50}\right)$ values ranging from 0.089 to $3.435 \mu \mathrm{g} / \mathrm{ml}$, and the mean $\mathrm{EC}_{50}$ was $1.515 \mu \mathrm{g} / \mathrm{ml}$. Out of 59 isolates collected from an orchard with a history of boscalid usage, 52 isolates had $\mathrm{EC}_{50}$ values ranging from 0.055 to $4.222 \mu \mathrm{g} / \mathrm{ml}$, and the mean $\mathrm{EC}_{50}$ was $1.214 \mu \mathrm{g} / \mathrm{ml}$. However, in vitro tests for conidial germination and mycelial growth also revealed that seven A. alternata isolates, originating from the orchard exposed to boscalid were highly resistant $\left(\mathrm{EC}_{50}>100 \mu \mathrm{g} / \mathrm{ml}\right)$ to this fungicide. Furthermore, in vitro tests showed no significant differences between wild-type and boscalidresistant mutants in some fitness parameters such as spore germination, hyphal growth, sporulation, or virulence on pistachio leaves. Experiments on the stability of the boscalid-resistant phenotype showed no reduction of the resistance after the mutants were grown on fungicide-free medium. Preventative applications of a commercial formulation of boscalid (Endura) at a concentration which is effective against naturally sensitive isolates failed to control disease caused by the boscalid-resistant isolates in laboratory tests. To our knowledge, this is first report of field isolates of fungi resistant to boscalid.
\end{abstract}

Additional keywords: boscalid resistance, carboxamides, predicted fitness

Alternaria late blight of pistachio caused by Alternaria spp. in the alternata, tenuissima, and arborescens species groups (34) is one of the most common fungal diseases of pistachio. The disease can cause severe premature defoliation, staining of nutshells, and molding of the kernels, which reduce fruit quality. On foliage, the disease is characterized by the development of large necrotic lesions that eventually coalesce and consume the entire leaf (34). Controlling Alternaria late blight requires a combination of cultural practices (irrigation management and pruning to increase air movement and reduce humidity in the orchard) and multiple fungicide sprays. Fungicides registered for control of the disease include sterol demethylation inhibitors (DMIs), benzimidazoles, and quinone outside inhibitors (QoI fungicides) (8). However, as observed for other fungal pathogens of plants, pesticide resistance is a major factor contributing to the ineffec-

Corresponding author: T. J. Michailides

E-mail: themis@uckac.edu

Accepted for publication 31 May 2007.

doi:10.1094/PDIS-91-10-1345

(C) 2007 The American Phytopathological Society tive management of Alternaria late blight of pistachio, particularly with systemic site-specific fungicides. For instance, a G143A mutation in the cytochrome b gene was associated with practical resistance to the QoI fungicide azoxystrobin (Abound) in Alternaria spp. Therefore, the use of these and related fungicides for controlling Alternaria late blight in California pistachio orchards was compromised in only a few years after the registration of strobilurins $(21,23,24,29)$.

One alternative to achieve and optimize disease control and minimize the risk of resistance development is to incorporate new fungicides with contrasting modes of action into a spray program $(4,5,41)$. Boscalid (trade name Endura) is a new broadspectrum fungicide belonging to the carboxamides class. The carboxamide group of fungicides is composed of boscalid, carboxin, benodanil, furametpyr, penthiopyrad, flutolanil, mepronil, fenburam, and thifluzamide (9). The target of carboxamides is succinate ubiquinone reductase (succinate dehydrogenase [Sdh]) of complex II in the respiration chain $(6,18,19)$. However, boscalid does not inhibit the succinate reductase activity of the complex II, but the quinine reduction activity. Thus, it differs from other fungicides in both its mode and site of action. The enzyme com- plex succinate ubiquinone reductase is a functional part of the tricarboxylic cycle and the mitochondrial electron transport chain and catalyzes both the oxidation of succinate to fumarate and the reduction of quinine. The Sdh complex consists of four subunits, a flavoprotein (Fp) subunit (SdhA), an iron sulfur protein (Ip) subunit (SdhB), and two membrane-anchored protein subunits ( $\mathrm{SdhC}$ and $\mathrm{SdhD}$ ). The Fp and Ip subunits form the soluble part of the complex and carry the Sdh activity, whereas the SdhC and SdhD subunits anchor Fp and Ip to the membrane and carry the quinine reduction activity $(15,18)$. Then, due to its novel mode of action, boscalid can control pathogens which have developed resistance to other chemical classes of fungicides. Through the inhibition of complex II, it inhibits spore germination, germ tube elongation, mycelial growth, and sporulation and is registered for use against Botrytis cinerea and Sclerotinia, Alternaria, and Monilinia spp., powdery mildews, and other pathogens in fruit, vegetables, and vines. In pistachio, boscalid is not registered alone but recently has been introduced in mixture with pyraclostrobin (a strobilurin) in the product Pristine.

As experienced with QoI fungicides, single-site inhibitor fungicides such as boscalid generally are prone to resistance development in pathogens. However, fungicide resistance often is accompanied by fitness costs that may influence the risk of resistance build-up in the absence of selection pressure $(30,36)$. Thus, monitoring boscalid resistance in Alternaria alternata from pistachio and characterizing resistant isolates in terms of fitness are necessary for managing boscalid resistance in this fungus. A monitoring program could reveal early shifts in the pathogen's sensitivity to this fungicide before resistance develops to the point of disease control failure (i.e., field resistance), and the fitness characteristics of the resistant isolates could be used to predict the behavior of the entire population in the future, thereby providing an opportunity to make changes in fungicide recommendations.

Therefore, the objective of the present study was to assess the risk of resistance to boscalid fungicide in A. alternata populations by (i) comparing the sensitivity to boscalid of field isolates of A. alternata from a population "A" that has never been exposed to boscalid fungicide with those 
of a population "B" that had been exposed to boscalid for two consecutive years in two or three sprays per season as a premixture with pyraclostrobin in the product Pristine; and (ii) characterizing the resistant isolates in regard to fitness, ability to cause disease under fungicide pressure, and stability of resistance in fungicidefree-medium.

\section{MATERIALS AND METHODS}

Isolate collections. Wild type singlespore isolates of A. alternata for population A (not exposed to fungicide) were collected from two pistachio orchards in two locations: 37 single-spore isolates were collected in 2005 from an orchard located at Kearney Agricultural Center (Fresno County, CA) that has never been treated with any fungicide and 12 isolates were collected in 2000 and 2003 from a commercial orchard in Tulare County, CA before any Pristine exposure. These isolates were stored at $4^{\circ} \mathrm{C}$ on grade 40 silica gel. For the exposed population B (exposed to Pristine), 59 single-spore isolates of A. alternata were collected in 2005 from a commercial pistachio orchard, located in Kern County, where boscalid had been used for two consecutive years in two or three sprays per season as a premixture with pyraclostrobin (Pristine sprays).

To obtain isolates, leaves showing putative infections by Alternaria spp. were collected from the orchards. A small piece of tissue $(0.5$ by $0.5 \mathrm{~cm})$ was taken from the margin of the lesion, surface disinfected with $0.5 \%$ sodium hypochlorite (10\% commercial bleach) for $3 \mathrm{~min}$, rinsed with sterile water, and placed on acidified (25\% [vol/vol] lactic acid at $2.5 \mathrm{ml} / \mathrm{liter})$ Difco potato dextrose agar (APDA; Difco Laboratories, Detroit). The plates were incubated under cool white fluorescent lights at $24^{\circ} \mathrm{C}$ for 7 days. The resultant conidia on each plate were picked with a sterile inoculation loop and placed in 500 $\mu \mathrm{l}$ of sterile water to produce a spore suspension. A $20-\mu \mathrm{l}$ aliquot of the spore suspension was spread on a petri plate containing PDA. After incubation at $24^{\circ} \mathrm{C}$ for $16 \mathrm{~h}$ in darkness, the plates were examined with a dissecting microscope $(\times 15$ magnification) and a small agar plug with a single germinating spore was picked from each plate with the use of a sterile surgical blade and transferred to a new PDA plate. Identification of $A$. alternata was performed according to a previously established protocol (34).

Determination of $A$. alternata sensitivity to boscalid based on spore germination test. Technical grade boscalid (a.i. 98.4\%) (BASF Corporation, Research Triangle Park, NC) was dissolved in $100 \%$ acetone to provide stock solution containing $10 \mathrm{mg} / \mathrm{ml}$ and then added to $2 \%$ water agar (WA) to produce light concentrations: $0,0.001,0.005,0.01,0.05,0.5,0.1,1$, and $5.0 \mu \mathrm{g} / \mathrm{ml} \mathrm{medium}$. The concentration of acetone in all media never exceeded 1 $\mathrm{ml} / \mathrm{liter}$.

To make spore suspensions, a 5-mm mycelial plug of each isolate was transferred to a plate containing a quarterstrength PDA (10 g of PDA and $12 \mathrm{~g}$ of agar per liter of medium). Spore suspension $\left(10^{4}\right.$ spores $\left./ \mathrm{ml}\right)$ were prepared in distilled water from a 7-day-old culture. Then, 100- $\mu \mathrm{l}$ aliquots of the spore suspension were spread onto fungicide-amended or control plates. After incubation at $24^{\circ} \mathrm{C}$ in darkness for $16 \mathrm{~h}$, the percentage of spore germination (100 spores for each treatment) was estimated by viewing with a microscope. Each test for every isolate was performed twice for each concentration of the fungicide. The effective fungicide concentration to inhibit $50 \%$ of spore germination $\left(\mathrm{EC}_{50}\right)$ values were calculated for individual isolates by regressing the inhibition of spore germination against the logarithm of the fungicide concentration. Analyses of variation of $\mathrm{EC}_{50}$ values from two experiments were conducted using SAS Proc analysis of variance (ANOVA) followed by mean separation using Fisher's least significant difference (LSD) test in SAS (SAS Institute, Cary, NC). Because the results of the two experiments did not differ statistically $(P>0.05)$, the average $\mathrm{EC}_{50}$ values from two experiments for each isolate were used in the data analysis. Frequency distributions of $\mathrm{EC}_{50}$ values for boscalid were established for all tested isolates in each population. The $\mathrm{EC}_{50}$ values of population A were compared with those of population B using the Fisher's LSD of SAS.

Three additional concentrations at 1, 10, and $100 \mu \mathrm{g}$ a.i. boscalid $/ \mathrm{ml}$ were prepared to test the less sensitive isolates $\left(\mathrm{EC}_{50}\right.$ values $>5 \mu \mathrm{g} / \mathrm{ml}$ ) using procedures similar to those described above. Petri plates without the fungicide were prepared and used as controls. Isolates were considered highly resistant to boscalid if the $\mathrm{EC}_{50}$ value was $>100 \mu \mathrm{g} / \mathrm{ml}$. Isolates with estimated $\mathrm{EC}_{50}$ values $<5 \mu \mathrm{g} / \mathrm{ml}$ were considered sensitive to the fungicide.

Determination of $A$. alternata sensitivity to boscalid based on mycelial growth test. The effect of boscalid on mycelial growth was evaluated for the less sensitive isolates. Mycelial disks (5 $\mathrm{mm}$ in diameter) of the pathogen removed from the margins of 7-day-old culture were transferred to PDA amended with boscalid at concentrations of 1,10 , and $100 \mu \mathrm{g}$ a.i. boscalid/ml. Petri plates without the fungicide were used as controls. For each isolate, two replicates per concentration were used. The radial growth (colony diameter) of each isolate was measured in two perpendicular directions, with the original mycelial plug diameter $(5 \mathrm{~mm})$ subtracted from this measurement, after 7 days of incubation at $24^{\circ} \mathrm{C}$ in the dark. For each isolate, a linear regression of the percentage of inhibition related to the control of mycelial growth versus the $\log 10$ transformation for each of the six concentrations of boscalid was obtained. $\mathrm{EC}_{50}$ values were calculated for individual isolates using a linear equation. Analyses of variation of $\mathrm{EC}_{50}$ values from two experiments were conducted using SAS Proc ANOVA followed by mean separation using Fisher's LSD in SAS (SAS Institute). Because the results of the two experiments did not differ statistically $(P>0.05)$, the average $\mathrm{EC}_{50}$ values from two experiments for each isolate were used in the data analysis.

Efficacy of Endura in controlling disease caused by boscalid-sensitive and boscalid-resistant isolates. The protective activity of boscalid for control of Alternaria late blight was tested under laboratory conditions on detached pistachio leaves as described by Ma et al. (22). Fully expanded detached pistachio leaves were surface disinfested in $0.5 \%$ sodium hypochlorite (10\% commercial bleach) for 3 min and then washed three times in sterilized water. After drying the excess water for $30 \mathrm{~min}$ on a bench at a laboratory, the leaves were sprayed with Endura (commercial formulation of boscalid) (BASF Corporation) at the rate of $0.1 \mathrm{~g} / \mathrm{liter}$ (dosage applied in fungicide trials conducted in California pistachio fields to obtain efficacy data for registration of Endura on pistachio; 27) with a handheld sprayer until numerous droplets were deposited onto the leaves. Leaves sprayed with water were used as a control. After droplets on leaves dried, each leaf was slightly wounded on the midrib with a sterile needle. Each wounded leaf was inoculated with a 5-mm mycelial plug taken from the edge of a 5-day-old colony of each selected resistant and sensitive isolate. Two replicates (10 leaves per replicate) for each isolate were used, and the inoculated leaves were placed on a rack in a plastic container with water on the bottom and then incubated at $24^{\circ} \mathrm{C}$ for 9 days. The lesion length for each leaf was recorded. The efficacy of Endura (EE) in controlling disease was calculated using the following formula: $\mathrm{EE}=(\mathrm{LC}-\mathrm{LT}) / \mathrm{LC}$, where $\mathrm{LC}$ is the average lesion length (in centimeters) from 10 nontreated control leaves and LT is that from 10 leaves treated with Endura. The experiment was performed twice and data analyzed using ANOVA of SAS to determine the significant differences in disease lesion length and efficacy of Endura between resistant and sensitive isolates.

Study of fitness components and virulence on detached pistachio leaves. Fitness components of five selected boscalidresistant isolates and four boscalidsensitive isolates were assessed and compared on fungicide-free agar media. For mycelial growth rate, a mycelial plug (5 $\mathrm{mm}$ in diameter) for each selected isolate was transferred to a petri plate containing 
fungicide-free PDA. After incubation of plates at $24^{\circ} \mathrm{C}$ for 7 days in darkness, the mean colony diameter (minus the diameter of the inoculation plug) was measured. Spore germination rate was examined on WA media (2\%). Spore suspensions were prepared in distilled water as described above for fungicide spore germination tests and spread on a fungicide-free plate. After incubation at $24^{\circ} \mathrm{C}$ in darkness for $16 \mathrm{~h}$, the percentage of spore germination (100 spores for each treatment) was estimated under a microscope. For the measurement of spore production, PDA plates were inoculated with mycelial plugs as described above and incubated for 10 days at $24^{\circ} \mathrm{C}$ in the dark. To harvest conidia, plates were washed with $10 \mathrm{ml}$ of sterile distilled water. Each spore suspension was filtered through two layers of cheesecloth, and the numbers of conidia were estimated using a hemacytometer. Each experiment was performed twice. Data were subjected to an ANOVA performed with SAS, and values of resistant isolates were compared with those of sensitive isolates using Fisher's LSD.

Virulence of resistant and sensitive isolates was determined by measuring lesion growth rate on detached pistachio leaves following the method described above for in vivo testing of resistance. Fully expanded detached pistachio leaves (not treated with fungicide) were surface sterilized as previously described. A mycelial plug (5 $\mathrm{mm}$ in diameter) was taken from the margin of a 5-day-old colony and placed on the leaflet. Two replicates (10 leaves per replicate) for each isolate were used and then incubated in a moist chamber as described above at $24^{\circ} \mathrm{C}$ for 9 days. Lesion size then was recorded and significant differences were determined using Fisher's LSD.

Stability of boscalid-resistant isolates. To determine whether fungicide resistance was stable, the sensitivity to boscalid of seven boscalid-resistant mutants and three sensitive isolates was compared after seven transfers at 10-day intervals onto PDA plates with no fungicide. Fungicide sensitivity was based on the mycelial growth test. For this purpose, a mycelial plug (5 $\mathrm{mm}$ in diameter) of each isolate was transferred to fresh boscalid-free PDA every 10 days. After seven successive transfers, the boscalid-resistant mutant and boscalidsensitive isolates were transferred to new PDA plates amended with boscalid at concentrations of 1,10 , and $100 \mu \mathrm{g} / \mathrm{ml}$, and the $\mathrm{EC}_{50}$ values to boscalid were determined as described above for the mycelial growth tests. The obtained $\mathrm{EC}_{50}$ values were compared with those determined for the original isolates.

\section{RESULTS}

In vitro activity of boscalid on spore germination and mycelial growth of $A$. alternata. The analysis of the effect of boscalid on spore germination of the 59 isolates from population $\mathrm{B}$, collected from an orchard with 2 years of boscalid exposure, showed that the $\mathrm{EC}_{50}$ values for 52 isolates ranged from 0.055 to $4.222 \mu \mathrm{g} / \mathrm{ml}$ $\left(\right.$ mean $\mathrm{EC}_{50}$ value $\left.=1.214 \mu \mathrm{g} / \mathrm{ml}\right)$. The $\mathrm{EC}_{50}$ values for the seven remaining isolates could not be estimated accurately because spore germination was not inhibited by more than $50 \%$, even on the highest concentration tested $(5 \mu \mathrm{g} / \mathrm{ml})$. The $\mathrm{EC}_{50}$ values of the isolates in this group clearly exceeded $5 \mu \mathrm{g} / \mathrm{ml}$ and were further tested at concentrations up to $100 \mu \mathrm{g} / \mathrm{ml}$. Values of $\mathrm{EC}_{50}$ were obtained and all seven isolates were found to be highly resistant to boscalid because the $\mathrm{EC}_{50}$ values obtained exceeded $100 \mu \mathrm{g} / \mathrm{ml}$. Frequency distribution of $\mathrm{EC}_{50}$ to boscalid for these $59 \mathrm{~A}$. alternata isolates is presented in Figure 1.

The seven A. alternata boscalid-resistant isolates, displaying $\mathrm{EC}_{50}$ values for spore germination above $100 \mu \mathrm{g} / \mathrm{ml}$, were further tested by mycelial growth on boscalid. All the resistant isolates were found resistant to boscalid regarding mycelial growth $\left(\mathrm{EC}_{50}>100 \mu \mathrm{g} / \mathrm{ml}\right)$, whereas the $\mathrm{EC}_{50}$ values of the three selected sensitive isolates tested were about $1 \mu \mathrm{g} / \mathrm{ml}$.

Of the 49 wild-type A. alternata isolates collected from pistachio orchards without a prior history of boscalid applications (population A), only 1 isolate (Y1) showed high resistance to boscalid. The $\mathrm{EC}_{50}$ for the other 48 isolates ranged from 0.089 to $3.435 \mu \mathrm{g} / \mathrm{ml}$, with mean $\mathrm{EC}_{50}$ value of $1.515 \mu \mathrm{g} / \mathrm{ml}$, whereas the $\mathrm{EC}_{50}$ for the isolate $\mathrm{Y} 1$ was $>100 \mu \mathrm{g} / \mathrm{ml}$. Frequency distribution of $\mathrm{EC}_{50}$ to boscalid for these 49 wild-type A. alternata isolates is presented in Figure 1.

Efficacy of boscalid (Endura) in vivo. Laboratory inoculation tests demonstrated that when boscalid (Endura) was not applied, five selected resistant and three selected sensitive isolates caused similar lesion lengths (no statistical difference) on detached pistachio leaves. However, when Endura was applied at the dose of 0.1 $\mathrm{g} /$ liter on the leaves before inoculation with Alternaria spp., all three selected sensitive isolates caused significantly smaller lesions than the resistant isolates (Table 1). The efficacy of Endura in controlling disease caused by these resistant isolates was significantly lower than that caused by the sensitive isolates (Table 1).

Spore germination, mycelial growth, and sporulation rates on fungicide-free media, and virulence on pistachio, of boscalid-resistant and -sensitive isolates.

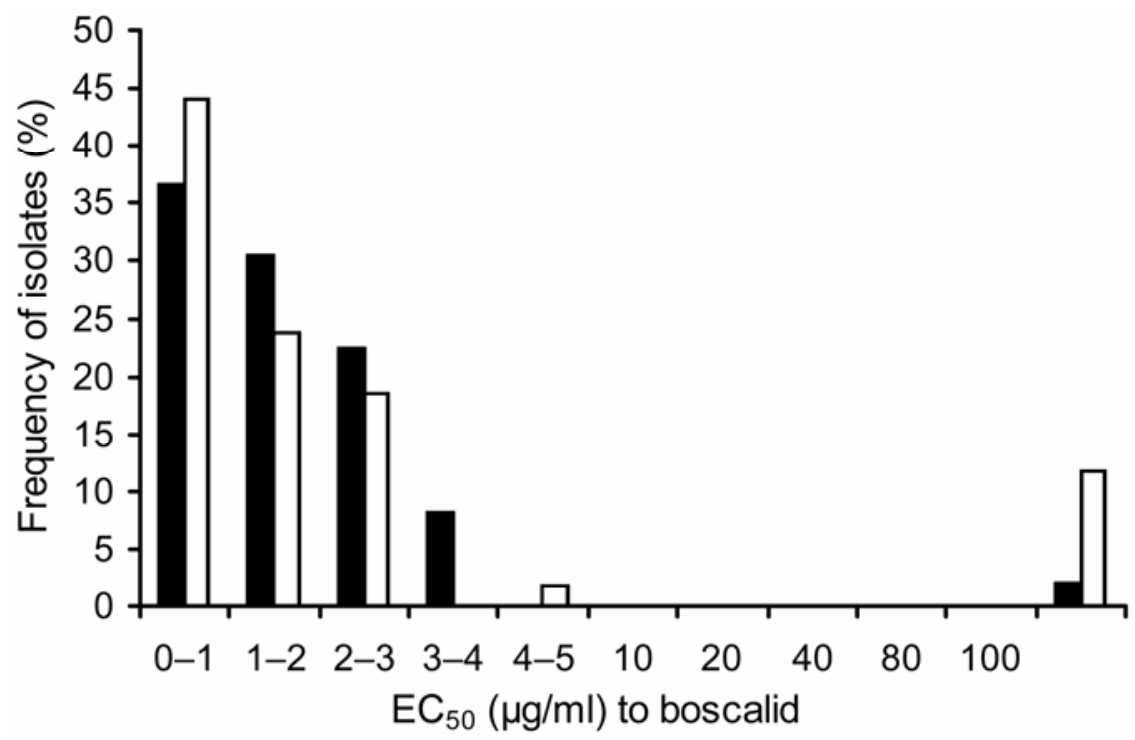

Fig. 1. Frequencies distributions of effective fungicide concentration to inhibit $50 \%$ of spore germination $\left(\mathrm{EC}_{50}\right)$ values to boscalid for 59 Alternaria alternata isolates collected from a commercial pistachio orchard with two consecutive years of boscalid exposure (white bars) and for 49 wild-type $A$. alternata isolates from pistachio orchards without a previous history of boscalid exposure (black bars).

Table 1. Comparison in lesion length and efficacy of Endura (EE) between boscalid-sensitive and boscalid-resistant isolates in laboratory inoculation tests ${ }^{\mathrm{z}}$

\begin{tabular}{lccc}
\hline & \multicolumn{2}{c}{ Lesion length $(\mathbf{c m})$} & \\
\cline { 2 - 3 } Isolates & Nontreated & Treated & Efficacy of Endura $(\boldsymbol{\%})$ \\
\hline Boscalid-sensitive & $2.22 \mathrm{a}( \pm 0.08)$ & $1.20 \mathrm{~b}( \pm 0.27)$ & $46.22 \mathrm{a}( \pm 9.83)$ \\
Boscalid-resistant & $2.82 \mathrm{a}( \pm 0.27)$ & $2.77 \mathrm{a}( \pm 0.36)$ & $1.80 \mathrm{~b}( \pm 12.80)$ \\
\hline
\end{tabular}

${ }^{z}$ Values within a column represent means of two experiment for all sensitive and resistant isolates tested because there were no significant differences between the two experiment $(P>0.05)$ in lesion length and efficacy of Endura for each isolate. Values in each column followed by the same letter are not significantly different at $P=0.05$ according to Fisher's least significant difference of SAS. Values $( \pm)$ in parentheses represent standard errors. 
Five boscalid-resistant $A$. alternata isolates in population B and four selected A. alternata boscalid-sensitive isolates were tested for their fitness and aggressiveness on pistachio. There were no significant differences $(P>0.05)$ in mycelial growth between resistant and sensitive isolates (Table 2). The percentage of germination of conidia for all boscalid-resistant and boscalid-sensitive isolates on nonamended medium was over $86 \%$ and there were no significant differences $(P>0.05)$ among the two group of isolates (Table 2). Regarding the sporulation parameter, various values among our selected boscalidresistant and boscalid-sensitive A. alternata isolates were observed. The smallest value for one individual sensitive (isolate Aa4) was $3.3 \times 10^{-5}$ and the largest value was $5.2 \times 10^{-5}$ (isolate AaY16). The smallest value for one individual resistant isolate was $1.86 \times 10^{-5}$ (isolate Aa20) and the largest value was $32.1 \times 10^{-5}$ (isolate Aa29). However, the mean value obtained for all resistant isolates was not significantly different $(P>0.05)$ from that observed for all tested sensitive isolates (Table 2). All the resistant and sensitive isolates tested were able to cause lesions on untreated detached leaves, and lesions ranged from 2.06 to $2.23 \mathrm{~cm}$ in diameter and from 1.80 to $2.60 \mathrm{~cm}$ in diameter, respectively, for the sensitive and resistant isolates, after 9 days. There were no significant differences in mean lesion length values $(P>0.05)$ between sensitive and resistant isolates (Table 2).

Stability of boscalid-resistant isolates. The resistant isolates of A. alternata maintained their resistance level through seven transfers on fungicide-free PDA over 3 months, with $\mathrm{EC}_{50}$ values for mycelial growth $>100 \mu \mathrm{g} / \mathrm{ml}$, whereas the $\mathrm{EC}_{50}$ values for three representative sensitive isolates maintained in the same conditions were 1.212 (one isolate) and $<1 \mu \mathrm{g} / \mathrm{ml}$ (two isolates).

In this study, the response of A. alternata populations originating from California pistachio orchards with and without boscalid exposure has been described. One isolate highly resistant to boscalid was identified in the collection of isolates from a pistachio orchard with no exposure to

\section{DISCUSSION}

boscalid and seven isolates highly resistant to boscalid were collected from the exposed orchard. The frequency of resistant isolates from the exposed orchard $(12 \%)$ was significantly $(P<0.05)$ higher than that $(2 \%)$ in the unexposed orchard. The detection of one boscalid-resistant isolate (isolate Y1) in the orchard where no boscalid sprays have been made indicates that resistance can preexist in pistachio orchards at very low frequencies. This assertion regarding the origin of this isolate is in accordance with the concept of fungicide resistance development stipulating that resistant alleles are often rare or nonexistent in fungal populations prior to the use of a particular fungicide. Such resistant alleles also can evolve in a population and spread rapidly, especially through airborne pathogen populations, and more particularly if selection pressure is maintained $(4,30,45)$. The nontreated orchard where the isolate Y1 was collected in 2005 is located 6.5 to $12.5 \mathrm{~km}$ away from orchards that have been exposed to boscalid. Therefore, it is possible that this isolate may have originated from a field where this fungicide has been applied. In several monitoring studies, long-distance dispersal of fungal conidia by wind from areas treated with fungicides already has been given as a reason to explain the presence of fungicide-resistant isolates in areas in which no fungicide was applied $(3,7$, 14,32). The detection of seven boscalidresistant isolates in population B suggests that the use of this fungicide can promote the selection of $A$. alternata isolates with high resistance to boscalid. Boscalid is used to control other important crop fungal pathogens, but no field or laboratory mutants resistant to boscalid of the target pathogens have been found thus far $(20,25,33,39,40)$ and this is the first report where a fungal pathogen has been shown to be resistant to boscalid.

The frequency distributions of fungicide sensitivity determined for boscalid show two separate populations of resistant and sensitive isolates in both populations $\mathrm{A}$ and B. This partitioning into two distinct groups of different sensitivity to boscalid suggests that resistance to boscalid occurs as a result of disruptive selection and is likely to be monogenic in nature, as expected for single-site inhibitor fungicides

Table 2. Comparison in spore germination, colony diameter, sporulation capacity, and lesion length between boscalid-sensitive and boscalid-resistant Alternaria alternata isolates from pistachio in laboratory tests ${ }^{\mathrm{z}}$

\begin{tabular}{lccccc}
\hline Phenotype & $\begin{array}{c}\text { Isolate } \\
\text { no. }\end{array}$ & $\begin{array}{c}\text { Spore germination } \\
\text { rate }(\boldsymbol{\%})\end{array}$ & $\begin{array}{c}\text { Colony } \\
\text { diameter }(\mathbf{c m})\end{array}$ & $\begin{array}{c}\text { Sporulation }(\mathbf{n o} \text { of } \\
\text { conidia } \times \mathbf{1 0} / \mathbf{m l})\end{array}$ & $\begin{array}{c}\text { Lesion diameter } \\
(\mathbf{c m})\end{array}$ \\
\hline Sensitive & 4 & $93.50 \mathrm{a}( \pm 3.32)$ & $4.94 \mathrm{a}( \pm 0.94)$ & $22.55 \mathrm{a}( \pm 21.61)$ & $2.11 \mathrm{a}( \pm 0.10)$ \\
Resistant & 5 & $91.90 \mathrm{a}( \pm 4.31)$ & $5.80 \mathrm{a}( \pm 0.56)$ & $17.40 \mathrm{a}( \pm 11.68)$ & $2.40 \mathrm{a}( \pm 0.34)$ \\
\hline
\end{tabular}

z Values within a column represent means of two experiment for all sensitive and resistant isolates tested because there were no significant differences between the two experiment $(P>0.05)$ in each parameter. Values in each column followed by the same letter are not significantly different at $P=$ 0.05 according to Fisher's least significant difference of SAS. Values $( \pm)$ in parentheses represent standard errors.
$(10,11)$. Point mutations in an $S d h$ gene, the target of action of the carboxanilide fungicide group, have been shown to confer resistance to carboxin and flutolanil, which are also carboxamides fungicides $(9,43)$, in carboxin-resistant and flutolanilresistant populations of some Ascomycete and Basidiomycete fungi $(6,13,15,17$, 26,38). Given the fact that boscalid, carboxin, and flutolanil belong to the same chemical group, we could infer that there is a cross resistance between them in the boscalid-resistant A. alternata detected in this study. It is currently under investigation whether the mutations identified in an Sdh gene in Mycosphearella graminicola (38), Ustilago maydis (6), Coprinus cinereus (15), and Paracoccus denitrificans (26) are the mechanisms responsible for boscalid resistance in A. alternata from pistachio.

During the course of this study, the baseline sensitivity values of A. alternata to boscalid were established. In fungicide resistance management, data on the sensitivity of a pathogen to new chemistry is needed before the fungicide is used widely to serve as baseline information to illustrate shifts in pathogen sensitivity and to provide evidence that control failures occurring in the future could be due to the appearance of resistance in the population $(16,35,44)$. Baseline sensitivities of some important fungal pathogens of other crops to the carboxamide fungicide boscalid has been established. The $\mathrm{EC}_{50}$ values to boscalid for spore germination for 36 isolates of another Alternaria sp. (i.e., A. mali) ranged from 0.003 to $1.592 \mu \mathrm{g} / \mathrm{ml}$ (20). The average $\mathrm{EC}_{50}$ for the isolates of this Alternaria sp. was $0.342 \mu \mathrm{g} / \mathrm{ml}$, which is low compared with the mean $\mathrm{EC}_{50}$ values $(1.36 \mu \mathrm{g} / \mathrm{ml})$ obtained for all wild type A. alternata isolates from pistachio in our study. Minimum inhibitory concentration (MIC) values of boscalid against Monilinia laxa and $M$. fructigena ranged from 0.01 to $2.5 \mu \mathrm{g} / \mathrm{ml}$ and from 0.039 to $2.5 \mu \mathrm{g} / \mathrm{ml}$, respectively (39). In $B$. cinerea, the minimum inhibitory concentration of boscalid of some isolates ranged between 0.1 and $3.0 \mu \mathrm{g} / \mathrm{ml}(40)$. At a boscalid concentration of $5 \mu \mathrm{g} / \mathrm{ml}$, spore germination for resistant isolates of $A$. alternata was not or weakly affected (ranged from 0 to $9.75 \%$; average $6.54 \%$ ). At the same concentration, boscalid strongly inhibited spore germination of all the sensitive isolates. Because this concentration clearly differentiates the sensitive and resistant phenotypes, it could be useful in a future monitoring program as a discriminatory dose for detection of resistance to boscalid when using spore germination methods. Interestingly, the $\mathrm{EC}_{50}$ values of $40 \mathrm{~A}$. alternata isolates obtained with the mycelial growth method in this study were lower than those determined for the same isolates using the spore germination method (data not shown), suggesting that mycelial growth may be 
more sensitive than spore germination in evaluating the inhibitory effects of boscalid fungicides against $A$. alternata isolates from pistachio. Similar results were obtained by Stammer and Speakman (40), who observed that spores of $B$. cinerea isolates continued to germinate in the presence of boscalid even at the highest concentration, whereas germ tube elongation was completely stopped. Because the mycelial inhibition test seems more sensitive to determine the boscalid sensitivity in $A$. alternata isolates, this test could be proposed as the preferred method for future monitoring studies.

In this study, predicted fitness components (1) of boscalid-resistant and boscalid-sensitive isolates and the stability of resistance have been evaluated. There are no studies on the fitness of field or laboratory mutants resistant to boscalid. Information on fitness of resistant mutants is useful in developing resistance avoidance and management strategies. Indeed, if such resistant isolates in the pathogen population display a lower fitness compared with the sensitive isolates, their frequency will decline when fungicide selection pressure is discontinued in the field (1). The results obtained have shown that the resistant isolates were not impaired in any of the fitness parameters tested on agar media. The virulence of resistant isolates on detached pistachio leaves also was examined in absence and presence of boscalid treatment. No significant difference in the ability to cause disease was observed between the resistant and the sensitive isolates, when considering this parameter in the absence of the fungicide. Similar studies, with several strains of $U$. maydis transformed with the carboxin resistance gene, and carboxin-resistant field isolates of $U$. nuda, have shown that these mutants were not significantly altered in their pathogenicity towards Zea mays and Hordeum vulgare, respectively $(31,42)$. By contrast, applications of Endura prior to inoculation with boscalidresistant isolates failed to control Alternaria late blight whereas, as expected, disease caused by the sensitive isolates was well controlled. In barley plants treated with carboxin, the level of infection caused by carboxin-sensitive isolates of $U$. $n u d a$ was also significantly lower than that observed with the carboxin-resistant isolates (31). Regarding the stability of resistance, the results obtained have shown that the resistance level of resistant isolates did not decline following successive subculturing on fungicide-free PDA, indicating that the resistance to boscalid apparently is stable in the absence of selection pressure. These data suggest that $A$. alternata boscalidresistant isolates appear to be as fit as the sensitive isolates and would be likely to rapidly increase to a dominant level within a population context, causing difficulty in controlling Alternaria late blight.
Although boscalid (Endura) is not registered in pistachio, it is used in mixture with pyraclostrobin (a QoI fungicide) in a registered premix fungicide product named Pristine and it is used as a strategy to manage the widespread resistance to strobilurins established among the A. alternata populations in pistachio orchards (29). The study of the sensitivity of the Alternaria isolates used in this report to pyraclostrobin shows that $95 \%$ of the isolates from the orchard treated with Pristine were resistant to pyraclostrobin (2). However, as described in this study, boscalid was effective against the majority of these isolates, showing that the use of this fungicide has significant impact in controlling Alternaria late blight in fields where QoI resistance has become common. The boscalidresistant isolates detected were also resistant to pyraclostrobin, indicating that boscalid exerts selection pressure on pyraclostrobin-resistant subpopulations and this leads to the selection of isolates simultaneously resistant to both fungicides (2). Disease control failures by Pristine in some fields were reported by growers in some areas and the appearance of isolates having this double phenotype possibly could play an important role in the decreased performance of this fungicide.

In summary, the data presented here demonstrate that there is a risk of A. alternata developing resistance to boscalid in the field over time. It is interesting to note how quickly boscalid resistance occurred in A. alternata subpopulations (only 2 years after the introduction of Pristine). Resistance to QoI fungicides occurred at a similarly high speed in several plant pathogens (only 2 years after introduction, in some cases), including Alternaria of pistachio, and has resulted in practical resistance $(12,14,21,37,46)$. However, our results, despite the detection of resistance, have demonstrated the good performance of boscalid, even if the sample size of isolates investigated was small. Nevertheless, the frequency of isolates prone to qualitative selection by boscalid could be increased in A. alternata populations. Therefore, practical anti-resistance strategies should be considered to reduce the selection of boscalid-resistant isolates in order to prolong the useful life of this fungicide. To this end, reducing the number of Pristine applications (usually two to three applications per season) to one treatment per year would be a valuable tool in resistance management. Moreover, combinations or alternations of Pristine with noncarboxamide fungicides registered for Alternaria late blight should be used, particularly in areas where reduced sensitivity to carboxamides (boscalid) and also QoI has been observed. The use of a protectant fungicide such as chlorothalonil (Bravo) or pyrimethanil (Scala), a member of the anilinopyrimidine fungicide class recently registered in pistachio, which have been proven to be a highly effective fungicides (28), may be suitable rotation partners in an Alternaria late blight management program. Boscalid (Endura) is also commonly used for the control of diseases caused by other important phytopathogenic fungi. Therefore, it is likely that resistant isolates of these pathogens would also appear. Thus, to prevent fungicide resistance problems, the application of this fungicide should be based on a prediction model that minimizes its use.

\section{ACKNOWLEDGMENTS}

We thank Y. Luo for helping with statistical analysis and H. Reyes and D. Felts for collecting infected leaves from pistachio orchards to collect the isolates.

\section{LITERATURE CITED}

1. Antonovics, J., and Alexander, H. M. 1989. The concept of fitness in plant-fungal pathogen systems. Pages 185-214 in: Plant Disease Epidemiology, Vol. 2. K. J. Leonard, and W. E. Fry, eds. McGraw-Hill Publishing Co., New York.

2. Avenot, H., Morgan, D. P., and Michailides, T. J. 2007. Multiple resistance to pyraclostrobin and boscalid confers resistance to Pristine (pyraclostrobin + boscalid) fungicide in Alternaria alternata causing Alternaria late blight of pistachios in California. Pages 105-112 in: California Pistachio Commission Production Research Reports, Crop Year 2006. California Pistachio Industry, Fresno, CA.

3. Baroffio, C. A., Siegfried, W., and Hilber, U. W. 2003. Long-term monitoring for resistance of Botryotinia fuckeliana to anilinopyrimidine, phenylpyrrole and hydroxyanilide fungicides in Switzerland. Plant Dis. 87:662-666.

4. Brent, K. J. 1995. Fungicide resistance in crop pathogens, How can it be managed? GCPF FRAC, Brussels, Monogr. 1:1-48.

5. Brent, K. J., and Hollomon, D. W. 1998. Fungicide resistance: the assessment of risk, FRAC, Global Crop Protection Federation, Brussels, Monogr. 2:1-48.

6. Broomfield, P. L. E., and Hargreaves, J. A 1992. A single amino-acid change in the ironsulphur protein subunit of succinate dehydrogenase confers resistance to carboxin in Ustilago maydis. Curr. Genet. 22:117-121.

7. Foster, B., and Staub, T. 1996. Basis for use strategies of anilinopyrimidine and phenylpyrrole against Botrytis cinerea. Crop Prot. 15:529-537.

8. Fungicide Resistance Action Committee. 2006. FRAC code list 1: Fungicides sorted by FRAC code. Online publication.

9. Fungicide Resistance Action Committee. 2006 FRAC code list 2: fungicides sorted by modes of action. Online publication.

10. Georgopoulos, S. G. 1994. Early evaluation of fungicide resistance risk. Pages 389-396 in: Fungicide Resistance BCPC Monograph No. 60. S. Heaney, D. Slawson, D. W. Hollomon, M. Smith, P. E. Russel, and D. W. Parry, eds. Farnham, UK.

11. Georgopoulos, S. G., and Skylakakis, G. 1986 Genetic variability in the fungi and the problem of fungicide resistance. Crop Prot. 5:5:299-305.

12. Gisi, U., Sierotzki, H., Cook, A., and McCaffery, A. 2002. Mechanism influencing the evolution of resistance to QoI inhibitor fungicides Pest Manage. Sci. 58:859-867.

13. Gunatilleke I. A. U. N., Arst H. N., and Scazzocchio, C. 1976. Three genes determine the carboxin sensitivity of mitochondrial succinate oxidation in Aspergillus nidulans. Genet Res. 26:297-305. 
14. Ishii, H., Fraaije, B. A., Sugiyama, T., Noguchi, K., Nishimura, K., Takeda, T., Amano, T., and Hollomon, D. W. 2001. Occurrence and molecular characterization of strobilurin resistance in cucumber powdery mildew and downy mildew. Phytopathology 91:1166-1171.

15. Ito, Y., Muraguchi, H., Seshime, Y., Oita, S., and Yanagi, S. O. 2004. Flutolanil and carboxin resistance in Coprinus cinereus conferred by a mutation in the cytochrome $b_{560}$ subunit of succinate dehydrogenase complex (Complex II). Mol. Gen. Genomics 272:328-335.

16. Justum, A. R., Heany, S. P., Perrin, B. M., and Wege, P. J. 1998. Pesticide resistance: Assessment of risk and implementation of effective management strategies. Pestic. Sci. 54:435446.

17. Keon, J. P. R., White, G. A., and Hargreaves, J. A. 1991. Isolation, characterization and sequence of a gene conferring resistance to the systemic fungicide carboxin from the maize smut pathogen, Ustilago maydis. Curr. Genet. 19:475-481.

18. Kita, K., Takamiya, S., Furushima, R., Villagra, E., Wang, H., Aoki, T., and Oya, H. 1991. Molecular organization of Complex II and its role in anaerobiosis. Prog. Neuropathol. 7:21-30.

19. Kuhn, P. J. 1984. Mode of action of carboximides. Symp. Ser. Br. Mycol. Soc. 9:155-183.

20. Lu, Y., Ma, J., Sutton, T. B., and Ypema, H. 2004. Comparison of two assay methods for evaluating the sensitivity of Alternaria mali to boscalid. (Abstr.) Phytopathology 94:S63.

21. Ma, Z., Felts, D., and Michailides, T. J. 2003. Resistance to azoxystrobin in Alternaria isolates from pistachio in California. Pestic. Biochem. Physiol. 77:66-74.

22. Ma, Z., and Michailides, T. J. 2004. Characterization of iprodione -resistance Alternaria isolates from pistachio in California. Pestic. Biochem. Physiol. 80:75-84.

23. Ma, Z., and Michailides, T. J. 2004. An allele specific PCR assay for detecting azoxystrobinresistant Alternaria isolates from pistachio. J. Phytopathol. 152:118-121.

24. Ma, Z., and Michailides, T. J. 2004. A realtime PCR assay for detection of azoxystrobinresistant Alternaria populations from pistachio orchards in California. Crop. Prot. 223:12591263.

25. Matheron, M. E., and Porchas, M. 2004. Activ- ity of boscalid, fenhexamid, fluazinam, fludioxonil, and vinclozolin on growth of Sclerotinia minor and $S$. sclerotiorum and development of lettuce drop. Plant Dis. 88:665-668.

26. Matsson, M., Ackrell, B. A., Cochran, B., and Hederstedt, L. 1998. Carboxin resistance in Paracoccus denitrificans conferred by a mutation in the membrane-anchor domain of succinate: quinine reductase. Arch Microbiol. 170:27-37.

27. Michailides, T. J., Morgan, D. P., Felts, D., and Reyes, H. 2005. Chemical control of Alternaria late blight of California pistachio in 2004. Pages 5-31 in: California Pistachio Commission Production Research Reports Crop Year 2005.

28. Michailides, T. J., Morgan, D. P., Felts, D., and Reyes, H. 2007. Chemical control of Alternaria late blight of California pistachio and evaluation of models to predict disease development in 2006. Pages 23-32 in: California Pistachio Commission Production Research Reports Crop Year 2006.

29. Michailides, T. J., Morgan, D. P., Ma, Z., Luo, Y., Felts, D., Doster, M. A., and Reyes, H. 2005. Conventional and molecular assays aid diagnosis of crop diseases and fungicide resistance. Calif. Agric. 59(2):115-123.

30. Milgroom, M. G., Levin, S. A., and Fry, W. E. 1989. Population genetics theory and fungicide resistance. Pages 341-367 in: Plant Disease Epidemiology, vol. 2. K. J. Leonard and W. E. Fry, eds. McGraw-Hill, New York.

31. Newcombe, G., and Thomas, P. L. 2000. Inheritance of carboxin resistance in a European field isolate of Ustilago nuda. Phytopathology 90:179-182.

32. Northover, J., and Homeyer, C. A. 2001. Detection and management of myclobutanilresistant grapevine powdery mildew (Uncinula necator) in Ontario. Can. J. Plant Pathol. 23:337-345.

33. Pasche, J. S., Piche, L. M., and Gudmestad, N. C. 2005. Effect of the F129L mutation in $\mathrm{Al}$ ternaria solani on fungicides affecting mitochondrial respiration. Plant Dis. 89:269-278.

34. Pryor, B., and Michailides, T. J. 2002. Morphological, pathogenic, and molecular characterization of Alternaria isolates associated with Alternaria late of pistachio. Phytopathology. 92:406-416.
35. Russel, P. E. 2004. Sensitivity baselines in fungicide resistance research and management, FRAC, Crop Life International, Brussels, Monogr. 3:1-60.

36. Shaw, M. W. 1989. A model of the evolution of polygenically controlled fungicide resistance. Plant Pathol. 38:44-55.

37. Sierotzki, H., Parisi, S., Steinfeld, U., Tenzer, I., Poirey, S., and Gisi, U. 2000. Mode of resistance to respiration inhibitors at the cytochrome bc1 enzyme complex of Mycosphaerella fijiensis field isolates. Pest Manage. Sci. 56:833-841.

38. Skinner, W., Bailey, A., Renwick, A., Keon, J., Gurr, S., and Hargreaves, J. A single aminoacid substitution in the iron-sulphur protein subunit of succinate dehydrogenase determines resistance to carboxin in Mycosphaerella graminicola. 1998. Curr. Genet. 34:393-398.

39. Spiegel, J., and Stammler, G. 2006. Baseline sensitivity of Monilinia laxa and M. fructigena to pyraclostrobin and boscalid. J. Plant Dis. Prot. 113(5).

40. Stammler, G., and Speakman, J. Microtiter Method to test the sensitivity of Botrytis cinerea to Boscalid. 2006. J. Phytopathol. 154:508510.

41. Staub, T. 1991. Fungicide resistance: Practical experience with antiresistance strategies and the role of integrated use. Annu. Rev. Phytopathol. 29:421-442.

42. Topp, C. N., Ruiz-Herrera, J., MartinezEspinosa, A., and Gold, S. E. 2002. Integration of the gene carboxin resistance does not impact the Ustilago maydis-maize interaction. Curr. Microbiol. 44(1):67-70.

43. Ulrich, J. T., and Mathre, D. E. 1972. Mode of action of oxathiin systemic fungicides. V. Effect on electron transport system of Ustilago maydis and Saccharomyces cerevisiae. J. Bacteriol. 110:628-632.

44. Uresh, P. A., Staub, T., and Voss, G. 1997. Resistance as a concomitant of modern crop protection. Pestic. Sci. 51:227-234.

45. Vendite, L. L., and Ghini, R. 1999. A mathematical model for fungal population growth and the fungicide resistance problem. J. Biol Syst. 7:239-249.

46. Vincelli, P., and Dixon, E. 2002. Resistance to QoI (strobilurin like) fungicides in isolates of Pyricularia grisea from perennial ryegrass. Plant Dis. 86:235-240. 